\title{
Competition in depleting resource environments shapes the thermal response of population fitness in a disease vector
}

Paul Huxley ( $\sim$ p.huxley@imperial.ac.uk)

Imperial College London https://orcid.org/0000-0001-9211-9479

Kris Murray

Imperial College London

Samraat Pawar

Imperial College London

Lauren Cator

Imperial College London https://orcid.org/0000-0002-6627-1490

\section{Article}

Keywords: climatic warming, population models, ecology

Posted Date: June 25th, 2021

DOI: https://doi.org/10.21203/rs.3.rs-624494/v1

License: (9) This work is licensed under a Creative Commons Attribution 4.0 International License.

Read Full License

Version of Record: A version of this preprint was published at Communications Biology on January 19th, 2022. See the published version at https://doi.org/10.1038/s42003-022-03030-7. 


\section{Title: Competition in depleting resource environments shapes the thermal response of population}

fitness in a disease vector

4

5

Paul J. Huxley ${ }^{1}$, Kris A. Murray ${ }^{1,2}$, Samraat Pawar $^{3}$, Lauren J. Cator ${ }^{3}$

${ }^{1}$ MRC Centre for Global Infectious Disease Analysis, School of Public Health, Imperial College London, London, UK. ${ }^{2} \mathrm{MRC}$ Unit The Gambia at London School of Hygiene \& Tropical Medicine, Banjul, The Gambia. ${ }^{3}$ Department of Life Sciences, Imperial College London, Ascot, UK. 


\begin{abstract}
Mathematical models that incorporate the temperature dependence of lab-measured life history traits are increasingly used to predict how climatic warming will affect ectotherms, including disease vectors and other arthropods. These temperature-trait relationships are typically measured under laboratory conditions that ignore how conspecific competition in depleting resource environments - a commonly occurring scenario in nature-regulates natural populations. Here, we used laboratory experiments on the mosquito Aedes aegypti, combined with a stage-structured population model, to show that intensified larval competition in ecologically-realistic depleting resource environments can significantly diminish the vector's maximal population-level fitness across the entire temperature range, cause a $6^{\circ} \mathrm{C}$ decrease in the optimal temperature for fitness, and contract its thermal niche width by $10^{\circ} \mathrm{C}$. Our results provide evidence for future studies to consider competition dynamics under depleting resources when predicting how eukaryotic ectotherms will respond to climatic warming.
\end{abstract}




\section{INTRODUCTION}

Global environmental change is predicted to affect the spatiotemporal distributions of arthropods, including disease vectors and the diseases they transmit (Mordecai et al. 2020; WHO 2020). For example, a recent study suggests that climatic warming may increase the thermal suitability for Zika virus transmission, leading to 1.3 billion more people being at risk of exposure by 2050 (Ryan et al. 2021). Other studies have predicted that warming will increase the global invasion potential of Aedes aegypti, a principal vector of dengue, yellow fever and chikungunya (Iwamura et al. 2020). Such predictions typically arise from mathematical models that incorporate thermal performance curves (TPCs) for vector life history traits, such as juvenile development and mortality, which together define the TPC of maximal population growth rate ( $r_{\mathrm{m}}$, a measure of population fitness; Savage et al. 2004).

Typically, such trait-level TPC data come from larval populations reared under optimal food conditions in the laboratory (e.g., Shocket et al. 2020). However, recent studies suggest that many predictions of how vector populations will respond to climatic warming are likely to be biased. For example, when food is supplied at a constant rate, low resource availability in the larval stage can have a significant negative effect on temperature-trait relationships (Couret et al. 2014; Barreaux et al. 2018; Huxley et al. 2021). In particular, our recent work (Huxley et al. 2021) has shown that low-resource supply, through its adverse impact on juvenile traits, can significantly depress population fitness and decrease its predicted peak temperature. Despite such advances, resources in natural habitats are not constant and, in many, or arguably even most cases, deplete over time (Ostfeld \& Keesing 2000; Yang et al. 2008; Beltran et al. 2021). For example, Ae. aegypti is expected to be strongly regulated by conspecific competition between larvae (Southwood et al. 1972; Dye 1984), because this stage of the species' lifecycle is confined to small isolated water bodies that are susceptible to infrequent resource inputs and, therefore, resource depletion (Subra \& Mouchet 1984; Arrivillaga \& Barrera 2004; Barrera et al. 2006; Yee \& Juliano 2012).

As per-capita energy requirements intensify with increasing temperature, resource depletion rates and the strength of competition should also increase. These combined effects are bound to compromise the growth, development, and survival of individuals. These trait-level effects are then expected to propagate through the stage-structured population dynamics to affect the shape of the $r_{\mathrm{m}}$ TPC (Amarasekare \& Savage 2012; Huey \& Kingsolver 2019). This is because $r_{\mathrm{m}}$ is essentially proportional to the difference between biomass gained through consumption and that lost to respiration and mortality (Savage et al. 2004). Resource limitation and intensified competition would be expected to decrease $r_{\mathrm{m}}$ across temperatures, as they would both undermine biomass intake and elevate biomass loss.

Furthermore, if the rate of biomass loss increases faster than any increase in biomass gain with temperature, the thermal optimum of $r_{\mathrm{m}}\left(T_{\mathrm{opt}}\right)$ may also shift downwards (García-Carreras et al. 2018). For the same reason, the range of temperatures over which $r_{\mathrm{m}}$ is positive (the thermal niche width) may become narrower. As a result, the combined effects of climatic warming and decreased resource availability could contribute to the contraction of species range boundaries. This effect could simultaneously decrease the burden of vector-borne diseases and agricultural pests but increase the extinction risk of vulnerable species (Amarasekare 2019; Lehmann et al. 2020). Conversely, concurrent increases in temperature and resource availability with climatic warming could have the opposite effect by optimising $r_{\mathrm{m}}$, and thus, promoting the invasion and establishment of tropical taxa into temperate habitats (Amarasekare \& Simon 2020). This effect could further increase the huge socioeconomic cost of invasions by disease vectors, such as Aedes mosquitoes (Diagne et al. 2021).

Studies across a broad range of taxa are needed to make generalisable predictions on the ecological impacts of environmental change on ectotherm populations, including disease vectors (Cross et al. 2015; Mordecai et al. 2019). So far, however, the effects of competition in depleting resource environments on the temperature dependence of ectotherm fitness have mainly focused on single-celled prokaryotes (Thomas et al. 2017; Bestion et al. 2018; Siegel et al. 2020). To address this important deficit, we investigated the effects of competition on the $r_{\mathrm{m}}$ TPC by exposing Ae. aegypti larvae to an ecologically-realistic range of temperatures and depleting resource levels. We show that competition in 
resource depletion scenarios will significantly change the shape of the thermal response of mosquito population fitness - key for predicting how disease vectors and other arthropods will respond to environmental change. Our findings allow us to infer that there are thresholds of resource availability, below which intensifying competition causes a sudden change in this temperature dependence of fitness.

\section{RESULTS}

All trait responses varied significantly with temperature and resource level, with a significant interaction between the two environmental variables (figure 1, tables 1,2).

Larval competition at our lowest resource level $\left(0.183 \mathrm{mg} \mathrm{ml}^{-1}\right)$ increased the negative effect of increased temperature on juvenile mortality rate (figure 1a, table 2 ). As temperatures increased from 22 to $34^{\circ} \mathrm{C}$, non-overlapping $95 \%$ credible intervals indicate that juvenile mortality rate was significantly higher at low-resource levels than at intermediate-resource levels $\left(0.367 \mathrm{mg} \mathrm{ml}^{-1}\right)$. At $0.183 \mathrm{mg} \mathrm{ml}^{-1}$, it increased by $\sim 300 \%$ from 0.05 at $22^{\circ} \mathrm{C}$ to 0.14 individual $^{-1}$ day $^{-1}$ at $34^{\circ} \mathrm{C}$. In contrast, at $0.367 \mathrm{mg} \mathrm{ml}^{-1}$, the juvenile mortality rate increased by $20 \%$ (from 0.04 to 0.05 individual $^{-1}$ day $^{-1}$ ) across this temperature range.

The interaction between temperature and resource level caused significant variation in development time across treatments (ANOVA; $F_{9,2.24}=13.44, p<0.001$, table 1 ). Development time decreased with temperature at all resource levels, but the decrease with temperature was greater at the low resource level than at higher resource levels due to resource depletion (figure 1b). At $0.183 \mathrm{mg} \mathrm{ml}^{-1}$, development time decreased from 18.30 days at $22^{\circ} \mathrm{C}$ to 8.26 days at $34^{\circ} \mathrm{C}$. Development time at the higher resource levels decreased from approximately 13.50 days at $22^{\circ} \mathrm{C}$ to $\sim 7.50$ days at $34^{\circ} \mathrm{C}$ (table 2).

Competition at low resource levels $\left(0.183 \mathrm{mg} \mathrm{ml}^{-1}\right)$ resulted in significant variation in size at maturity (mass, $\mathrm{mg}$ ) between resource levels (ANOVA; $F_{9,0.92}=24.26, p<0.001$, table 1). Adult size decreased both at warmer temperatures and at low-resource levels, though the decrease with temperature was greater at higher resource levels than at the low resource level. At low-resource levels, size decreased by $0.13 \mathrm{mg}$ as temperatures increased from 22 to $34^{\circ} \mathrm{C}$, while at the highest resource level $(0.733 \mathrm{mg}$ $\mathrm{ml}^{-1}$ ), size decreased by $0.26 \mathrm{mg}$ (figure $1 \mathrm{c}$, table 2 ).

The interaction between temperature and resource level caused significant variation in adult lifespan across treatments (ANOVA; $F_{9,699.60}=7.96, p<0.001$, table 1 ). Lifespan was greatest at $0.733 \mathrm{mg} \mathrm{ml}^{-1}$, where it was 11.24 days at $22^{\circ} \mathrm{C}, 11.65$ days at $26^{\circ} \mathrm{C}$, and 4.68 days at $34^{\circ} \mathrm{C}$. In contrast, at low resource levels, lifespan decreased from 8.00 days at $22^{\circ} \mathrm{C}$ to 3.76 days at $34^{\circ} \mathrm{C} \mathrm{mg} \mathrm{(figure} 1 \mathrm{~d}$, table 2).

At all resource levels, predicted daily fecundity rate increased with temperature (table 2), though the increase was greater at the lowest resource level than at higher resource levels. At the lowest resource level, fecundity increased with temperature from 1.77 eggs individual ${ }^{-1}$ day $^{-1}$ at $22^{\circ} \mathrm{C}$ to 6.87 eggs individual ${ }^{-1}$ day $^{-1}$ at $34^{\circ} \mathrm{C}$. At the higher resource levels, fecundity increased from $\sim 2$ eggs at $22^{\circ} \mathrm{C}$ to $\sim 5$ eggs individual ${ }^{-1}$ day $^{-1}$ at $34^{\circ} \mathrm{C}$. 
a

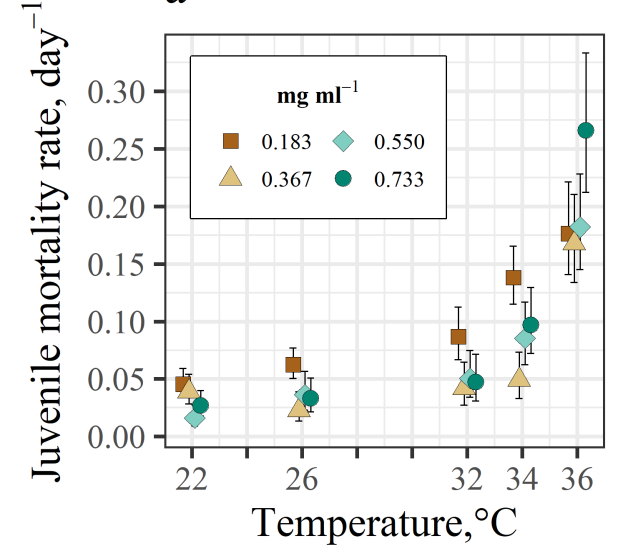

c

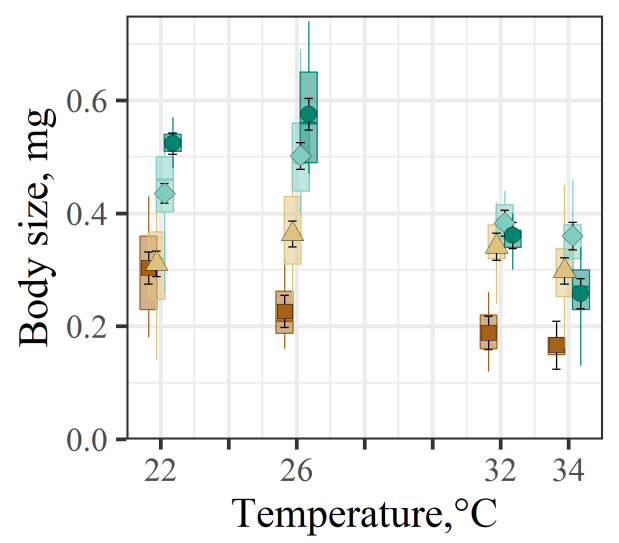

b

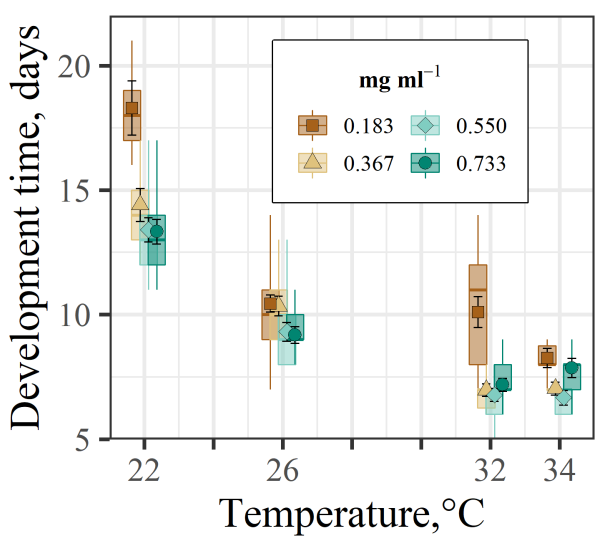

d

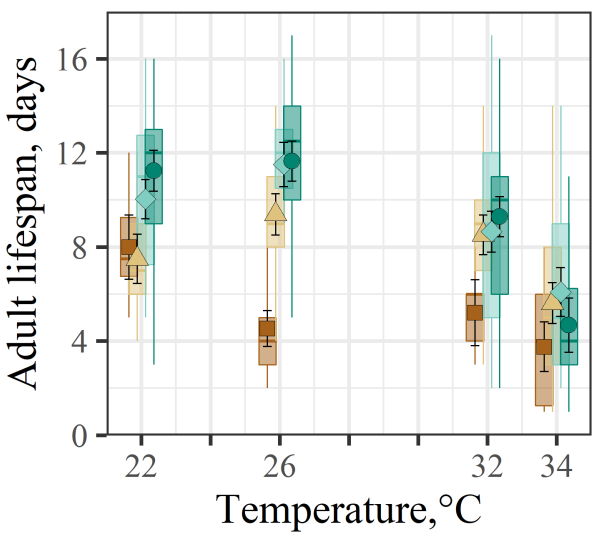

Figure 1. The effect of larval competition on fitness traits in Ae. aegypti with $95 \%$ credible intervals (CIs). a, Competition at low resource levels $\left(0.183 \mathrm{mg} \mathrm{ml}^{-1}\right)$ increased the negative effect of increased temperature on juvenile mortality. b, Development time decreased with temperature at all resource levels but, at most temperatures, it was significantly extended by competition at $0.183 \mathrm{mg} \mathrm{ml}^{-1}$. c, As temperatures increased from $22^{\circ} \mathrm{C}$, competition at $0.183 \mathrm{mg} \mathrm{ml}^{-1}$ significantly reduced size at emergence. $\mathbf{d}$, As temperatures increased from 22 to $32^{\circ} \mathrm{C}$, competition at $0.183 \mathrm{mg} \mathrm{ml}^{-1}$ significantly reduced adult lifespan. Symbols denote the regression estimated means with 95\% CIs calculated from the standard errors (replicate dropped, table 2) for the resource levels at each temperature. The resulting ANOVAs of the regressions for each trait are presented in table 1. Boxplot horizontal lines represent medians. Lower and upper hinges are the 25th and 75th percentiles. Upper whiskers extend from the hinge to the largest value no further than $1.5 \times$ inter-quartile range (IQR) from the hinge. The lower whisker extends from the hinge to the smallest value at most $1.5 \times \mathrm{IQR}$ of the hinge. 


\begin{tabular}{|c|c|c|c|c|c|}
\hline Trait & Predictor & $\chi^{2}$ & df & $F$ value & $p$ value \\
\hline \multirow{2}{*}{ Development time (GLM) } & Temperature & 50.28 & 3 & 903.40 & $<0.001 * * *$ \\
\hline & $\mathbf{R L}$ & 3.97 & 3 & 71.28 & $<0.001 * * *$ \\
\hline \multirow[t]{4}{*}{$R^{2}=0.83$} & Temperature $\times \mathbf{R L}$ & 2.24 & 9 & 13.44 & $<0.001 * * *$ \\
\hline & Replicate & 0.07 & 2 & 1.77 & 0.17 \\
\hline & Residuals & 12.63 & 681 & & \\
\hline & Temperature & 1594.80 & 3 & 54.44 & $<0.001 * * *$ \\
\hline Adult lifespan (LM) & $\mathbf{R C}$ & 1908.60 & 3 & 65.15 & $<0.001 * * *$ \\
\hline \multirow[t]{4}{*}{$R^{2}=0.41$} & Temperature $\times \mathbf{R L}$ & 699.60 & 9 & 7.96 & $<0.001 * * *$ \\
\hline & Replicate & 15.70 & 2 & 0.81 & 0.45 \\
\hline & Residuals & 6533.10 & 669 & & \\
\hline & Temperature & 1.32 & 3 & 104.92 & $<0.001 * * *$ \\
\hline Body size (LM) & $\mathbf{R C}$ & 2.58 & 3 & 204.38 & $<0.001 * * *$ \\
\hline \multirow[t]{3}{*}{$R^{2}=0.73$} & Temperature $\times \mathbf{R L}$ & 0.92 & 9 & 24.26 & $<0.001 * * *$ \\
\hline & Replicate & 0.02 & 2 & 2.31 & 0.10 \\
\hline & Residuals & 1.81 & 431 & & \\
\hline
\end{tabular}

Table 1. Type II Analysis of Variance results from mixed effect regression models fitted to the responses of life history traits to temperature and resource level (RL). Significant effects are shown in boldface type. * $\Rightarrow$ $p$ value $<0.05 ; * * \Rightarrow p$ value $<0.01 * * * \Rightarrow p$ value $<0.001$ 


\begin{tabular}{|c|c|c|c|c|c|}
\hline \multirow{3}{*}{ Trait } & \multirow{3}{*}{$\begin{array}{c}\text { Temperature } \\
\left({ }^{\circ} \mathbf{C}\right)\end{array}$} & \multicolumn{4}{|c|}{ "Resource level $\left(\mathrm{mg} \mathrm{ml}^{-1}\right)$} \\
\hline & & \multicolumn{4}{|c|}{ Mean \pm s.e.m. } \\
\hline & & 0.183 & 0.367 & 0.550 & 0.733 \\
\hline \multirow{4}{*}{ Development time (days) } & 22 & $18.30 \pm 0.56$ & $14.41 \pm 0.34$ & $13.41 \pm 0.25$ & $13.33 \pm 0.25$ \\
\hline & 26 & $10.45 \pm 0.18$ & $10.35 \pm 0.20$ & $9.32 \pm 0.19$ & $9.19 \pm 0.17$ \\
\hline & 32 & $10.11 \pm 0.32$ & $6.98 \pm 0.13$ & $6.78 \pm 0.13$ & $7.19 \pm 0.13$ \\
\hline & 34 & $8.26 \pm 0.19$ & $7.04 \pm 0.14$ & $6.67 \pm 0.15$ & $7.87 \pm 0.20$ \\
\hline \multirow{5}{*}{$\begin{array}{l}\text { Juvenile mortality rate } \\
\text { (individual }^{-1} \text { day }^{-1} \text { ) }\end{array}$} & 22 & $0.05 \pm 0.01$ & $0.04 \pm 0.01$ & $0.02 \pm 0.00$ & $0.03 \pm 0.01$ \\
\hline & 26 & $0.06 \pm 0.01$ & $0.02 \pm 0.01$ & $0.04 \pm 0.01$ & $0.03 \pm 0.01$ \\
\hline & 32 & $0.09 \pm 0.01$ & $0.04 \pm 0.01$ & $0.05 \pm 0.01$ & $0.05 \pm 0.01$ \\
\hline & 34 & $0.14 \pm 0.01$ & $0.05 \pm 0.01$ & $0.09 \pm 0.01$ & $0.10 \pm 0.01$ \\
\hline & 36 & $0.18 \pm 0.02$ & $0.17 \pm 0.02$ & $0.18 \pm 0.02$ & $0.27 \pm 0.03$ \\
\hline \multirow{4}{*}{ Adult lifespan (days) } & 22 & $8.00 \pm 0.70$ & $7.50 \pm 0.54$ & $10.04 \pm 0.43$ & $11.24 \pm 0.45$ \\
\hline & 26 & $4.54 \pm 0.39$ & $9.39 \pm 0.45$ & $11.51 \pm 0.48$ & $11.65 \pm 0.43$ \\
\hline & 32 & $5.21 \pm 0.72$ & $8.53 \pm 0.43$ & $8.66 \pm 0.44$ & $9.29 \pm 0.43$ \\
\hline & 34 & $3.76 \pm 0.54$ & $5.62 \pm 0.44$ & $6.09 \pm 0.53$ & $4.68 \pm 0.59$ \\
\hline \multirow{4}{*}{$\begin{array}{l}\text { Body size } \\
\text { (dry mass (mg)) }\end{array}$} & 22 & $0.30 \pm 0.01$ & $0.31 \pm 0.01$ & $0.44 \pm 0.01$ & $0.52 \pm 0.01$ \\
\hline & 26 & $0.23 \pm 0.01$ & $0.36 \pm 0.01$ & $0.50 \pm 0.01$ & $0.58 \pm 0.01$ \\
\hline & 32 & $0.19 \pm 0.01$ & $0.34 \pm 0.01$ & $0.38 \pm 0.01$ & $0.36 \pm 0.01$ \\
\hline & 34 & $0.17 \pm 0.02$ & $0.30 \pm 0.01$ & $0.36 \pm 0.01$ & $0.26 \pm 0.01$ \\
\hline \multirow{4}{*}{$\begin{array}{l}\text { Daily fecundity rate } \\
\text { (eggs individual }^{-1} \text { day }^{-1} \text { ) }\end{array}$} & 22 & $1.77 \pm 0.06$ & $1.95 \pm 0.05$ & $1.99 \pm 0.06$ & $2.59 \pm 0.54$ \\
\hline & 26 & $1.52 \pm 0.07$ & $1.96 \pm 0.08$ & $2.54 \pm 0.37$ & $3.00 \pm 0.30$ \\
\hline & 32 & $3.79 \pm 0.26$ & $3.04 \pm 0.33$ & $3.55 \pm 0.51$ & $2.64 \pm 0.22$ \\
\hline & 34 & $6.87 \pm 1.87$ & $5.07 \pm 0.82$ & $4.91 \pm 0.52$ & $5.76 \pm 0.89$ \\
\hline \multirow{5}{*}{ Population-level fitness $\left(r_{\mathrm{m}}\right)$} & 22 & $-0.05 \pm 0.03$ & $0.06 \pm 0.02$ & $0.10 \pm 0.01$ & $0.08 \pm 0.02$ \\
\hline & 26 & $0.05 \pm 0.02$ & $0.12 \pm 0.02$ & $0.14 \pm 0.02$ & $0.16 \pm 0.02$ \\
\hline & 32 & $-0.04 \pm 0.04$ & $0.24 \pm 0.03$ & $0.23 \pm 0.03$ & $0.20 \pm 0.03$ \\
\hline & 34 & $-0.21 \pm 0.05$ & $0.22 \pm 0.03$ & $0.15 \pm 0.04$ & $0.02 \pm 0.05$ \\
\hline & 36 & $-2.10 \pm 0.15$ & $-2.11 \pm 0.21$ & $-2.19 \pm 0.22$ & $-2.68 \pm 0.20$ \\
\hline
\end{tabular}
component traits. The means with standard errors for juvenile mortality rate were estimated by fitting an exponential function to each treatment. The means with standard errors for development time, lifespan and size were estimated by using the statistical models in table 1 (replicate dropped). For fecundity, the standard errors were estimated using the Rmisc package in R. For $r_{\mathrm{m}}, 95 \%$ CIs were approximated using the delta method (Skalski et al. 2007). For $r_{\mathrm{m}}$ TPC fitting, non-positive matrix projection $r_{\mathrm{m}}$ values at $36^{\circ} \mathrm{C}$ were adjusted to 0.30 . For plotting (figure 2a), non-positive $r_{\mathrm{m}}$ values were cut off at -0.10 . 


\section{Population fitness}

At all resource levels, $r_{\mathrm{m}}$ responded unimodally to temperature. However, intensified larval competition at low resource levels $\left(0.183 \mathrm{mg} \mathrm{ml}^{-1}\right)$ significantly depressed $r_{\mathrm{m}}$ across the entire temperature range (figure 2a) and caused it to peak at a significantly lower temperature than at intermediate resource levels $\left(0.367 \mathrm{mg} \mathrm{ml}^{-1}\right.$; figure $2 \mathrm{~b}$, table 3$)$. Competition at $0.183 \mathrm{mg} \mathrm{ml}^{-1}$ also significantly narrowed the thermal niche width for $r_{\mathrm{m}}$ compared to higher resource levels (figure 2a, table 3 ).

At $0.183 \mathrm{mg} \mathrm{ml}^{-1}, r_{\mathrm{m}}$ was negative until temperatures increased to $23.3^{\circ} \mathrm{C}$ (figure 2 , table 3 ). At this resource level, $r_{\mathrm{m}}$ reached a peak of 0.05 at its $T_{\text {opt }}\left(26.6^{\circ} \mathrm{C}\right)$; it then declined to negative growth at $30.1^{\circ} \mathrm{C}$. The breadth of $r_{\mathrm{m}}$ 's thermal niche width at the lowest resource level was $6.8^{\circ} \mathrm{C}$. In contrast, at the intermediate food level $\left(0.367 \mathrm{mg} \mathrm{ml}^{-1}\right), r_{\mathrm{m}}$ became positive as temperatures increased to $18.8^{\circ} \mathrm{C}$; it was maximal at $33.0^{\circ} \mathrm{C}(0.24$, figure 2 , table 3$)$. At $0.367 \mathrm{mg} \mathrm{ml}^{-1}, r_{\mathrm{m}}$ declined to negative growth at $35.4^{\circ} \mathrm{C}$. The thermal niche width for $r_{\mathrm{m}}$ at this resource level was $16.6^{\circ} \mathrm{C}$. Overlapping CIs indicate that the predicted differences between the intermediate resource level and the higher resource levels $(0.550$ and $0.733 \mathrm{mg} \mathrm{ml}^{-1}$ ) in $r_{\mathrm{m}}$ at $T_{\mathrm{opt}}, T_{\mathrm{opt}}$, and the thermal niche width were non-significant (figure 2 , table 3). 
a

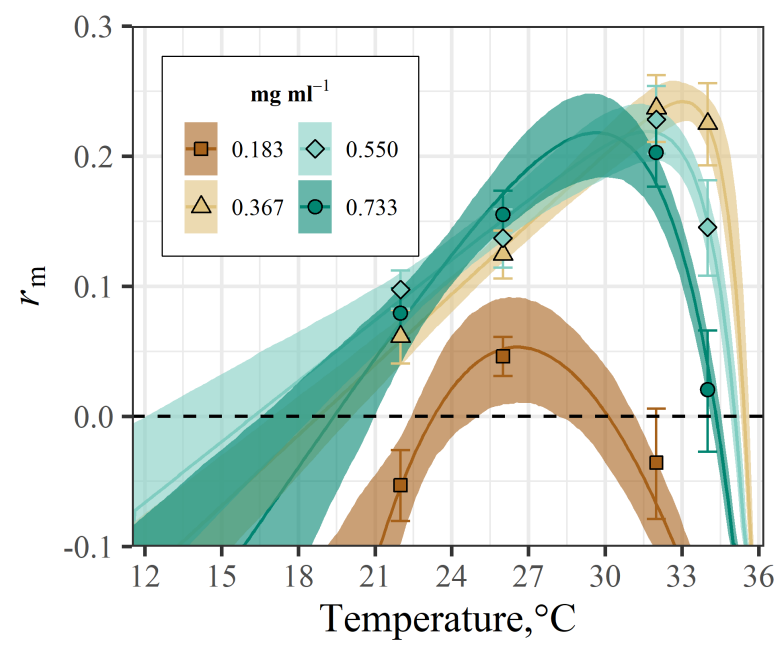

b

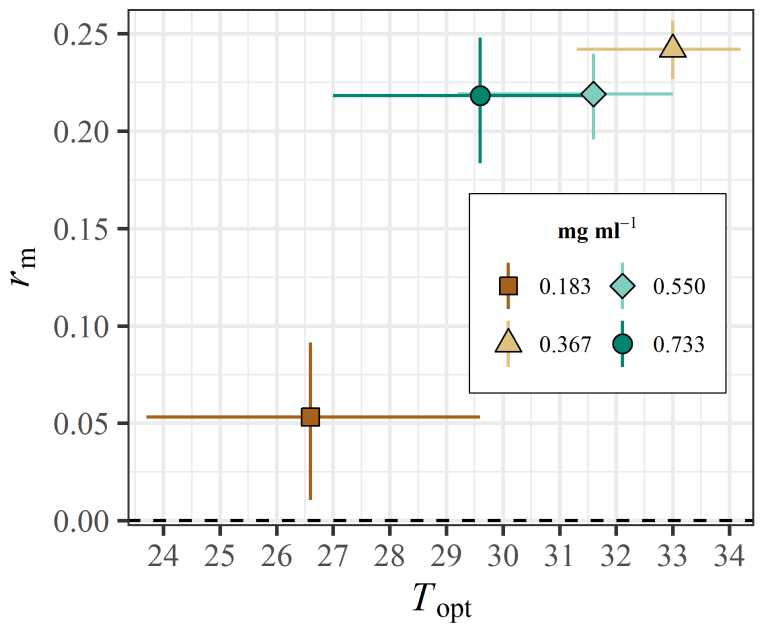

Figure 2. The effect of larval competition on the thermal response of population-level Ae. aegypti fitness $\left(r_{\mathrm{m}}\right)$ with bootstrapped $95 \%$ prediction bounds. a, Competition at $0.183 \mathrm{mg} \mathrm{ml}^{-1}$ significantly depressed $r_{\mathrm{m}}$ across the entire temperature range and narrowed its thermal niche width compared to the higher resource levels (non-overlapping 95\% prediction bounds, table 3). Symbols denote matrix projection estimates with 95\% confidence intervals (table 2). b, Competition at $0.183 \mathrm{mg} \mathrm{ml}^{-1}$ significantly (non-overlapping $95 \%$ confidence intervals) lowered maximal $r_{\mathrm{m}}$ and caused it to peak at a significantly lower temperature than at the intermediate resource level $\left(0.367 \mathrm{mg} \mathrm{ml}^{-1}\right)$. Predicted $r_{\mathrm{m}} T_{\mathrm{opt}}$ at $0.183 \mathrm{mg} \mathrm{ml}^{-1}$ indicates that competition could decrease $r_{\mathrm{m}} T_{\mathrm{opt}}$ by $6.4^{\circ} \mathrm{C}$, when compared to the intermediate resource level $\left(0.367 \mathrm{mg} \mathrm{ml}^{-1}\right.$, table 3$)$. 


\begin{tabular}{|c|c|c|c|c|c|}
\hline $\begin{array}{l}\text { Resource level } \\
\quad\left(\mathrm{mg} \mathrm{ml}^{-1}\right)\end{array}$ & $\begin{array}{c}\boldsymbol{r}_{\mathbf{m}} \text { at } \boldsymbol{T}_{\mathbf{o p t}} \\
( \pm 95 \% \mathrm{CI})\end{array}$ & $\begin{array}{c}\boldsymbol{T}_{\text {opt }}\left({ }^{\circ} \mathbf{C}\right) \\
(95 \% \mathrm{CI})\end{array}$ & $\begin{array}{l}\boldsymbol{T}_{\min }\left({ }^{\circ} \mathbf{C}\right) \\
(95 \% \mathrm{CI})\end{array}$ & $\begin{array}{l}\boldsymbol{T}_{\max }\left({ }^{\circ} \mathbf{C}\right) \\
(95 \% \mathrm{CI})\end{array}$ & $\begin{array}{c}\text { Thermal niche } \\
\text { width }\left({ }^{\circ} \mathbf{C}\right) \\
(95 \% \mathrm{CI})\end{array}$ \\
\hline 0.183 & $0.05 \pm 0.04$ & $\begin{array}{l}26.6 \\
(23.7-29.6)\end{array}$ & $\begin{array}{l}23.3 \\
(22.4-24.9)\end{array}$ & $\begin{array}{l}30.1 \\
(28.6-31.2)\end{array}$ & $\begin{array}{l}6.8 \\
(3.7-8.8)\end{array}$ \\
\hline 0.367 & $0.24 \pm 0.02$ & $\begin{array}{l}33.0 \\
(31.3-34.2)\end{array}$ & $\begin{array}{l}18.8 \\
(17.1-20.2)\end{array}$ & $\begin{array}{l}35.4 \\
(35.4-35.7)\end{array}$ & $\begin{array}{l}16.6 \\
(15.2-18.6)\end{array}$ \\
\hline 0.550 & $0.22 \pm 0.02$ & $\begin{array}{l}31.6 \\
(29.2-33)\end{array}$ & $\begin{array}{l}16.2 \\
(12.4-18.6)\end{array}$ & $\begin{array}{l}35.1 \\
(35.0-35.3)\end{array}$ & $\begin{array}{l}18.8 \\
(16.4-22.9)\end{array}$ \\
\hline 0.733 & $0.22 \pm 0.03$ & $\begin{array}{l}29.6 \\
(27.0-31.5)\end{array}$ & $\begin{array}{l}19.4 \\
(16.6-21.0)\end{array}$ & $\begin{array}{l}34.3 \\
(34.2-34.6)\end{array}$ & $\begin{array}{l}14.9 \\
(13.2-18)\end{array}$ \\
\hline
\end{tabular}

381

382

383

384

385

386

387

388

389

390

391

392

393

394

395

396

397

398

399

400

401

402

403

404

405

406

407

408

409

410

411

412

413

414

415

416

417

418

419

420

421

422

423
Table 3. Parameter estimates of the Thermal Performance Curves of $\boldsymbol{r}_{\mathbf{m}}$ by resource level. Non-overlapping 95\% Confidence Intervals (CIs) indicate that larval competition at the lowest resource level $\left(0.183 \mathrm{mg} \mathrm{ml}^{-1}\right)$ significantly depressed maximal growth $\left(r_{\mathrm{m}}\right.$ at $\left.T_{\mathrm{opt}}\right)$ compared to the higher resource levels. Competition at 0.183 $\mathrm{mg} \mathrm{ml}^{-1}$ caused a significant decrease in $r_{\mathrm{m}} T_{\mathrm{opt}}$ compared to $r_{\mathrm{m}} T_{\mathrm{opt}}$ at $0.367 \mathrm{mg} \mathrm{ml}^{-1}$; it also caused a significantly narrower thermal niche width compared to the higher resource levels. 


\section{Sensitivity analyses}

\section{Elasticities}

Juvenile traits (development time and survival) contributed more substantially to $r_{\mathrm{m}}$ than adult traits (figure 3). For example, at the lowest resource level $\left(0.183 \mathrm{mg} \mathrm{ml}^{-1}\right)$ at $26^{\circ} \mathrm{C}$, a 0.5 proportional increase in juvenile traits would increase rate of increase from 0.046 to 0.063 (figure 3d). By contrast, for the same treatment, increases of equal proportions in adult survival and fecundity would increase $r_{\mathrm{m}}$ from 0.046 to 0.050 (figure $3 \mathrm{e}$ ) and from 0.046 to 0.048 (figure $3 \mathrm{f}$ ), respectively This highlights how the temperature-dependence of $r_{\mathrm{m}}$ stems mainly from how competition impacts juvenile survival and development. Juvenile survival determines the number of reproducing individuals, whereas, development rate governs the timing of reproduction. The carry over effect of reduced size at maturity on $r_{\mathrm{m}}$ is relatively weak, because fecundity and adult survival have comparatively small effects on $r_{\mathrm{m}}$.

\section{Fecundity estimates}

Figure 4 shows that the $r_{\mathrm{m}}$ TPCs were insensitive to uncertainty in our fecundity estimates. Comparison with the central estimates shows that, for all resource levels, using the upper and lower $95 \%$ exponents (Supplementary file 1-Equation S1 and figure S1b) for the scaling between lifetime fecundity and size does not qualitatively change the predicted $r_{\mathrm{m}}$ TPCs, or the matrix projection $r_{\mathrm{m}}$ estimates that were used to fit the $r_{\mathrm{m}}$ TPCs. Predicted $r_{\mathrm{m}} T_{\mathrm{opt}}$ was also insensitive to uncertainty in our fecundity estimates. Also, using the upper and lower 95\% exponents (Supplementary file 1-Equation S1 and figure S1b) for the scaling between lifetime fecundity and size does not qualitatively change predicted maximal $r_{\mathrm{m}}$ or $r_{\mathrm{m}} T_{\mathrm{opt}}$. 
(a) $22^{\circ} \mathrm{C}$ Juvenile traits

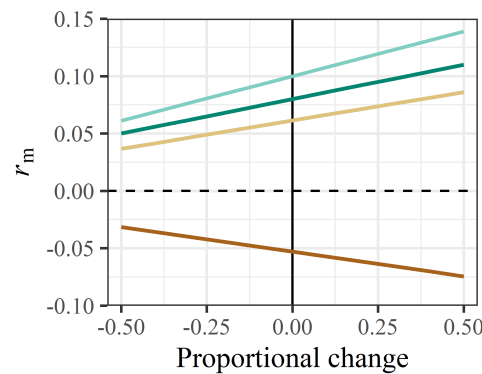

(d) $26^{\circ} \mathrm{C}$ Juvenile traits

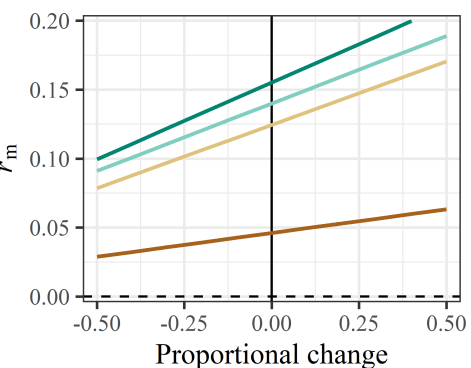

(g) $32^{\circ} \mathrm{C}$ Juvenile traits

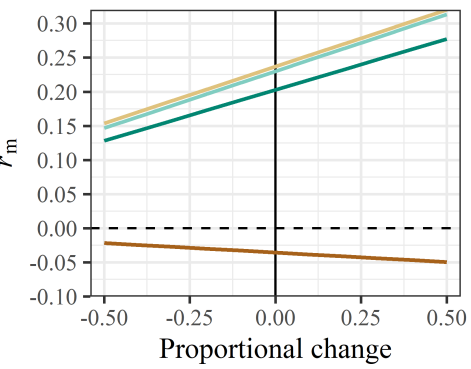

(j) $34^{\circ} \mathrm{C}$ Juvenile traits

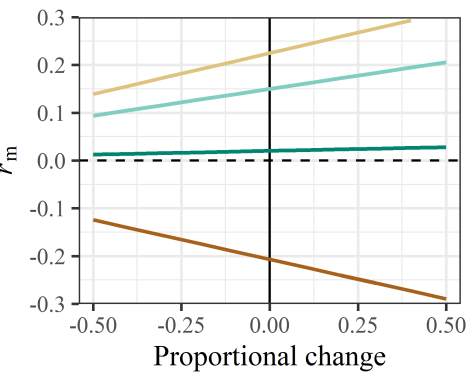

(m) $36^{\circ} \mathrm{C}$ Juvenile traits

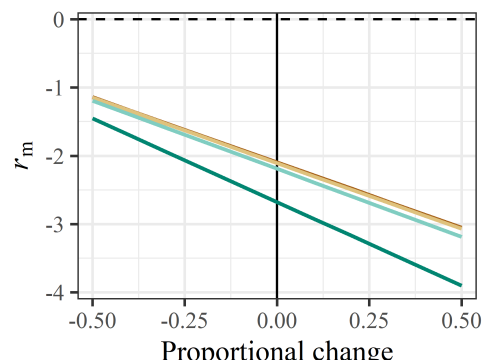

(b) $22^{\circ} \mathrm{C}$ Adult lifespan

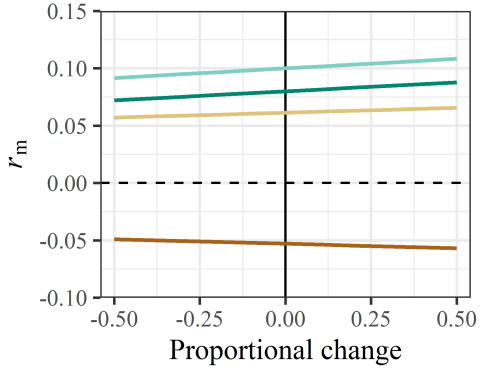

(e) $26^{\circ} \mathrm{C}$ Adult lifespan

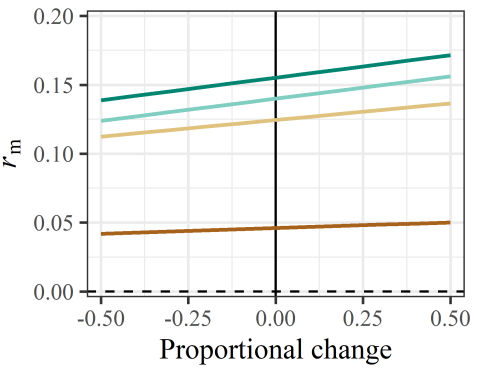

(h) $32^{\circ} \mathrm{C}$ Adult lifespan

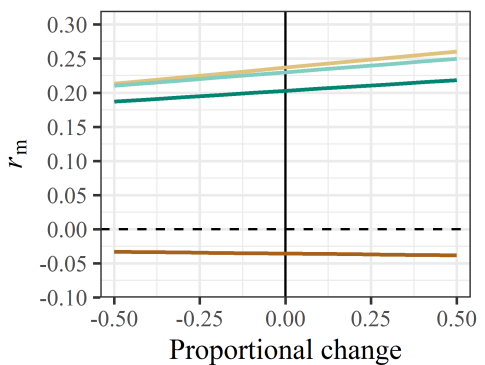

(k) $34^{\circ} \mathrm{C}$ Adult lifespan

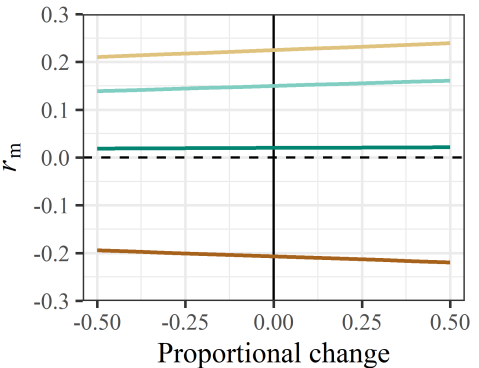

(c) $22^{\circ} \mathrm{C}$ Fecundity rate

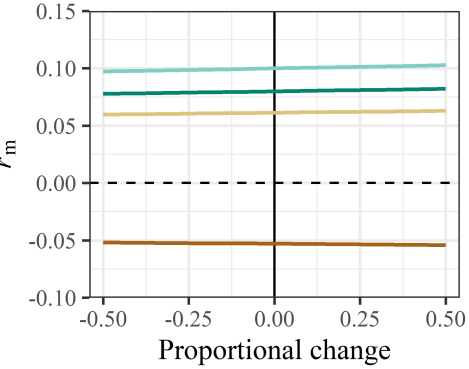

(f) $26^{\circ} \mathrm{C}$ Fecundity rate

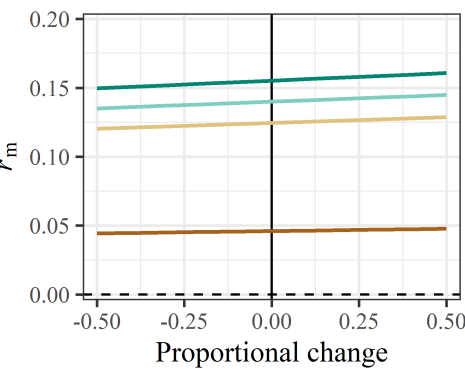

(i) $32^{\circ} \mathrm{C}$ Fecundity rate

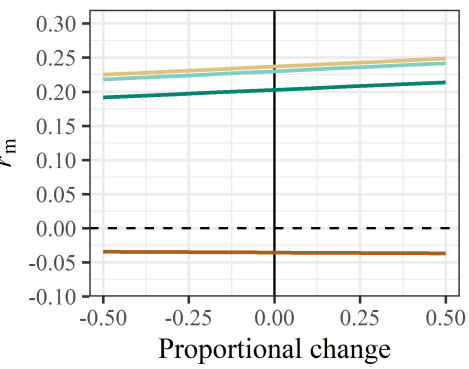

(1) $34^{\circ} \mathrm{C}$ Fecundity rate

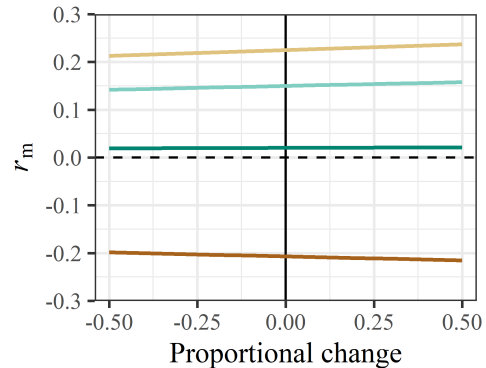
resource levels. Juvenile survival and development contributed more substantially to $r_{\mathrm{m}}$, as relatively small changes in the summed matrix elements for these traits would result in relatively large changes in $r_{\mathrm{m}}$. Sensitivity 
(a) $0.183 \mathrm{mg} \mathrm{ml}^{-1}$

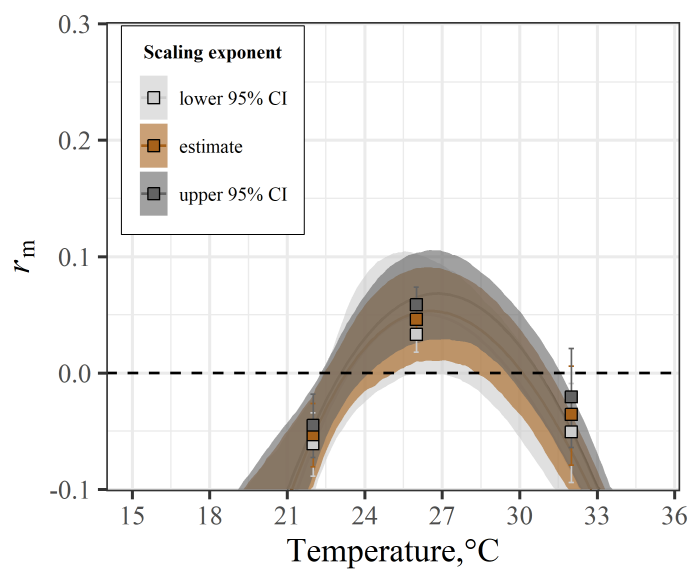

(c) $0.550 \mathrm{mg} \mathrm{ml}^{-1}$

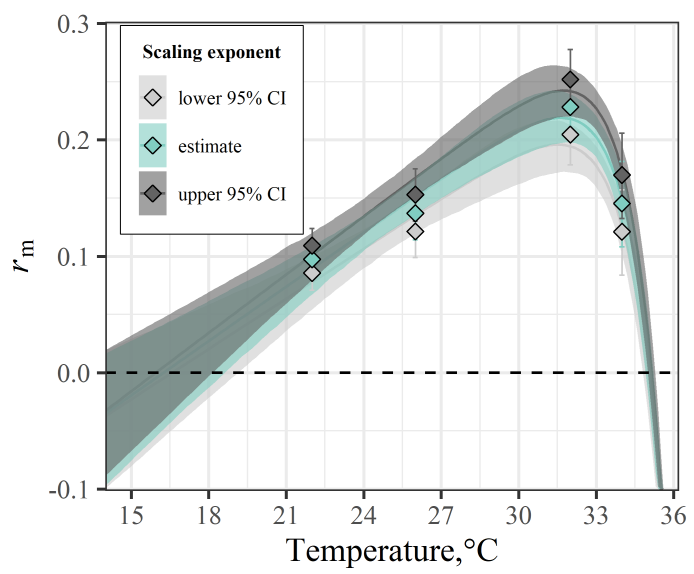

(e)

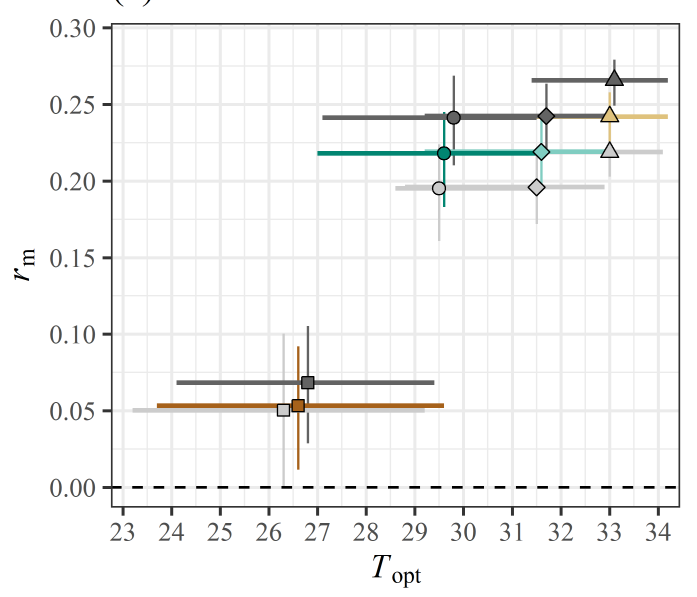

(b) $0.367 \mathrm{mg} \mathrm{ml}^{-1}$

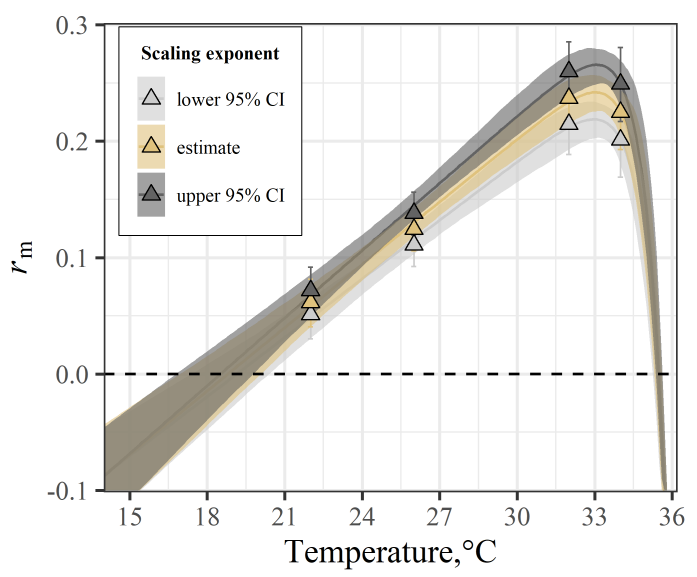

(d) $0.733 \mathrm{mg} \mathrm{ml}^{-1}$

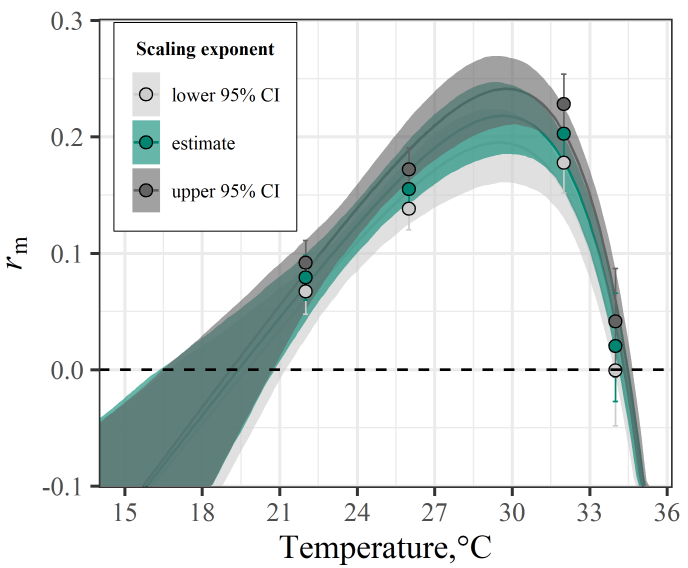

487

Figure 4. a-d, The insensitivity of the $r_{\mathrm{m}}$ TPCs to uncertainty in our fecundity estimates by resource level. Comparison with the central estimates (coloured lines and 95\% confidence bounds compared with greyscale lines and CBs) shows that, for all resource levels, using the upper and lower 95\% exponents (Supplementary file 1Equation S1, figure S1b) for the scaling between lifetime fecundity and size does not qualitatively change the predicted $r_{\mathrm{m}}$ TPCs, or the matrix projection $r_{\mathrm{m}}$ estimates (represented by symbols) that were used to fit the $r_{\mathrm{m}}$ TPCs. e, The insensitivity of predicted $r_{\mathrm{m}} \boldsymbol{T}_{\mathrm{opt}}$ to uncertainty in our fecundity estimates by resource level. Using the upper and lower 95\% exponents (Supplementary file 1-Equation S1, figure S1b) for the scaling between lifetime fecundity and size does not qualitatively change predicted maximal $r_{\mathrm{m}}$ (symbols with $95 \%$ CIs (vertical, coloured lines)) or $r_{\mathrm{m}} T_{\mathrm{opt}}$ (symbols with 95\% CIs (horizonal coloured lines)). 


\section{Discussion}

Previous studies on the effects of resource depletion on the temperature dependence of population fitness in ectotherms have mainly focused on single-celled organisms (Thomas et al. 2017; Bestion et al. 2018; Siegel et al. 2020). We show that larval competition in depleting resource environments can significantly change the shape of the $r_{\mathrm{m}}$ thermal response in Ae. aegypti. We also show that there are resource availability thresholds, below which competition intensifies, causing a dramatic change in the temperature dependence of fitness. Together, our findings indicate that competition in depleting resource environments is an important regulatory mechanism that needs to be considered when predicting how organisms with complex life cycles will respond to anticipated shifts in environmental temperature with global change.

At the lowest resource level $\left(0.183 \mathrm{mg} \mathrm{ml}^{-1}\right)$, competition had a consistent negative effect on the thermal responses of underlying fitness traits (figure 1), which caused a marked divergence between the $r_{\mathrm{m}}$ TPCs (figure 2). Competition at the lowest resource level significantly depressed $r_{\mathrm{m}}$ across the entire temperature range, caused a significant decrease $\left(\sim 6^{\circ} \mathrm{C}\right)$ in $r_{\mathrm{m}} T_{\mathrm{opt}}$ compared to the intermediate resource level $\left(0.367 \mathrm{mg} \mathrm{ml}^{-1}\right)$, and led to a $300 \%$ contraction of the $r_{\mathrm{m}}$ thermal niche width compared to the higher resource levels (figure 2, table 3 ).

The elasticity analysis shows that the key mechanism underlying the divergent temperature dependence of $r_{\mathrm{m}}$ across resource levels is increased juvenile development time and mortality at low resource levels (figure 3). The negative effect of competition at low-resource levels on these traits delayed the onset of reproduction and population-level reproductive output, respectively. This finding - that juvenile traits contribute more to $r_{\mathrm{m}}$ than adult traits - is consistent with general studies of fitness in organisms with complex lifecycles (Caswell 1978; Kammenga et al. 1996; Huey \& Berrigan 2001; Cator et al. 2020), including mosquitoes (Juliano 1998; Huxley et al. 2021).

Furthermore, individual fecundity rate and adult lifespan had negligible effects on $r_{\mathrm{m}}$ compared to juvenile traits, suggesting that the carry over effect of reduced size at maturity on $r_{\mathrm{m}}$ is relatively weak (figure 3). For example, at low-resource levels, lifetime fecundity was greater at $22^{\circ} \mathrm{C}$ than at $26^{\circ} \mathrm{C}$ because body size and adult lifespan were greater at $22^{\circ} \mathrm{C}$. Despite this difference, $r_{\mathrm{m}}$ at $26^{\circ} \mathrm{C}$ was predicted to be $\sim 200 \%$ greater than at $22^{\circ} \mathrm{C}$ (figures 1 and 2 , table 2). This result derives from how juvenile development time almost halved as temperatures increased from 22 to $26^{\circ} \mathrm{C}$ (table 2). Although juvenile mortality rates for these treatments were similar $\left(0.05\right.$ at $22^{\circ} \mathrm{C}$ versus 0.06 at $26^{\circ} \mathrm{C}$, table 2$)$, faster development at $26^{\circ} \mathrm{C}$ meant that greater numbers of individuals could contribute to population growth through reproductive output. This finding is consistent with recent studies that have used constant resource supply rates (Huxley et al. 2021) in suggesting that most projections of how warming will affect disease transmission through its effects on vector abundance are likely to be biased because they are likely to underestimate the effect of temperature on juvenile traits and overestimate its effect on adult traits.

Studies on how constant high-resource supply rates affect the temperature dependence of $r_{\mathrm{m}}$ in $A e$. Aegypti similarly report that the optimal temperature for growth in this species is $\sim 32^{\circ} \mathrm{C}$ (Farjana et al. 2012; Huxley et al. 2021). However, it appears that competition in depleting resource environments can have a negative effect on $r_{\mathrm{m}}$, even when initial resource levels are high. For example, Huxley et al. (2021) found that $r_{\mathrm{m}}$ at high-resource supply was 0.28 at $32^{\circ} \mathrm{C}$, whereas, it was 0.24 at $32^{\circ} \mathrm{C}$ at the optimal resource level $\left(0.367 \mathrm{mg} \mathrm{ml}^{-1}\right)$ for $r_{\mathrm{m}}$ in this study.

The trait-level responses at our higher resource levels are congruent with studies that have used the trait responses of optimally-fed lab strains to predict how vector fitness and disease transmission will respond to climatic warming. In these studies, mosquitoes are expected to develop at $\sim 0.07$ individual $^{-}$ ${ }^{1}$ day $^{-1}$ at $22^{\circ} \mathrm{C}$; increasing to $\sim 0.14$ individual $^{-1}$ day $^{-1}$ at $32^{\circ} \mathrm{C}$ (Mordecai et al. 2019). In the present study, development rate (1/development time; figure $1 \mathrm{~b}$, table 2$)$ increased by a similar margin when the strength of competition was lessened by high resource availability. In contrast, at low-resource levels, we found juvenile development rate increased from 0.05 day $^{-1}$ at $22^{\circ} \mathrm{C}$ to 0.12 day $^{-1}$ at $32^{\circ} \mathrm{C}$ 
(figure 1b, table 2). Although these differences in juvenile development rate may appear small, we show that they can have dramatic effects on the temperature dependence of $r_{\mathrm{m}}$ when combined with the negative impact of intensified competition on juvenile survival (figure 1a, table 2).

Juvenile mortality rate increased significantly with temperature and it was consistently higher at low resource levels (figure 1a) than at higher resource levels. This is probably because somatic maintenance costs increase with metabolic rate (Kooijman 2000), which cannot be met below a threshold resource level. Intensified competition at low resource levels is also likely to have contributed to preventing some individuals from meeting this increased energy demand. This explains why juvenile mortality rates were highest at 32 and $34^{\circ} \mathrm{C}$ at low-resource levels (except at $36^{\circ} \mathrm{C}$ where no individuals survived at all) where the energy supply-demand deficit was expected to be the largest.

Since larval competition can mediate the temperature dependence of $r_{\mathrm{m}}$, it is also important to determine the temperature dependence of resource availability itself (Huey \& Kingsolver 2019). For example, the natural diet of mosquito larvae comprises of detritus and microbial decomposers (Merritt et al. 1992), which are both sensitive to temperature (Craine et al. 2010; Smith et al. 2019). Therefore, shifts in environmental temperature could alter the concentration of food in the environment, which could affect the growth of detritivore populations. While recent studies have provided useful insights into the relationships between microbes, detritus and mosquito vectors (Yee et al. 2007; Chouaia et al. 2012; Dickson et al. 2017; Souza et al. 2019; Hery et al. 2021), future work could focus on the temperaturedependencies of these relationships.

Such a focus could provide important insights into how disease vectors and other arthropods will respond to environmental change. For example, if resource availability increases with climatic warming (e.g., due to increases in decomposition and microbial growth rates), its regulatory effect on population growth and abundance could be relaxed through increased juvenile development and adult recruitment rates. Indeed, increased resource availability with warming could contribute to the expansion of disease vectors and other invasive pest species into regions that were previously prohibitive by broadening $r_{\mathrm{m}}$ 's thermal niche width (Amarasekare \& Simon 2020; Lehmann et al. 2020). On the other hand, evidence from our high resource level treatments (e.g., a lower $T_{\mathrm{opt}}$ at 0.733 than at $0.367 \mathrm{mg} \mathrm{ml}^{-1}$ ) may suggest that warming could have a negative impact on population growth by causing resources to be overabundant, which could lead to eutrophication and hypoxia in aquatic environments (Liikanen et al. 2002).

Alternatively, if climate change reduces resource availability (e.g., by disrupting temperature-dependent consumer-resource relationships), species' spatiotemporal ranges could contract (Lister \& Garcia 2018; Huey \& Kingsolver 2019). This is because, as we have shown here, intensified competition at low food levels can prevent $r_{\mathrm{m}}$ from being positive at lower temperatures, can lower $r_{\mathrm{m}} T_{\mathrm{opt}}$, and can force $r_{\mathrm{m}}$ to become negative at lower temperatures. In this way, the effects of rising temperatures on vulnerable arthropod populations could be especially pernicious, if resource availability is simultaneously reduced (Huey \& Kingsolver 2019).

We used size-scaling to estimate the effect of temperature and resource level on fecundity, because it is anticipated that most of the effect of intensified larval competition at low-resource levels affects adult mosquitoes indirectly by reducing size at emergence and lifespan (Steinwascher 1982; Briegel 1990). Despite these assumptions, we show that substantial error in our fecundity estimates would not alter our main conclusions. This is because predicted fitness was relatively insensitive to these traits (figures 3 and 4).

Rapid global change is expected to have far-reaching and disruptive ecological impacts (Trisos et al. 2020). Climate-driven shifts in the spatiotemporal distributions and abundances of organisms are likely to cause widespread harm to ecosystems, biodiversity and society (Parmesan 2006; Diagne et al. 2021). This concern has prompted calls for a more complete understanding of how interactions between environmental factors can affect population-level responses (Cross et al. 2015; Huey \& Kingsolver 2019; Taheri et al. 2021). Attempts to understand the population-level effects of temperature $\times$ resource 
interactions have focused on prokaryotes or have not considered competition in depleting resource environments. Our study provides rare evidence of how intensified competition below certain resource thresholds can affect the temperature dependence of fitness in a predictable and generalisable way.

\section{Materials and Methods}

We investigated the effects of temperature and resource depletion on mosquito life history using a $5 \times 4$ factorial design comprised of five temperatures $\left(22,26,32,34\right.$, and $\left.36^{\circ} \mathrm{C}\right)$ and four resource levels $\left(0.183,0.367,0.550\right.$ and $\left.0.733 \mathrm{mg} \mathrm{ml}^{-1}\right)$. These experimental temperatures span the range of temperatures that this strain of Ae. aegypti (F16-19 originating from Fort Meyer, FL; (Bargielowski et al. 2013) is likely to experience in the wild between May (the onset of mosquito season) and November (Arguez et al. 2012). We extended our range to $36^{\circ} \mathrm{C}$ to determine the upper critical thermal limit for this strain. Our resource levels are within the range of studies that have investigated the effects of depleting larval resource environments on Ae. aegypti (Subra \& Mouchet 1984). Our lowest resource level $\left(0.183 \mathrm{mg} \mathrm{ml}^{-1}\right)$ was chosen to simulate a level of resource limitation that is expected in natural juvenile habitats (Arrivillaga \& Barrera 2004; Barrera et al. 2006). Further, our preliminary assays showed that resource levels below $0.183 \mathrm{mg} \mathrm{ml}^{-1}$ resulted in complete juvenile mortality.

The experiment was carried out in two randomised blocks. Each block consisted of all five temperatures and two resource levels. On Day 0 of each block, batches of approximately 800 eggs were deposited into five (one per experimental temperature) plastic tubs containing $300 \mathrm{ml}$ of dechlorinated tap water. We provided each tub with a pinch of powdered fish food (Cichlid Gold $\AA$, Hikari, Kyrin Food Industries Ltd., Japan) to prompt overnight hatching. Tubs were randomly assigned to a water bath (Grant Instruments: JAB Academy) set at one of the five experimental temperatures. Water baths were situated in a $20^{\circ} \mathrm{C}$ climate-controlled insectary with a 12L:12D photoperiod and 30 minutes of gradual transition of light levels to simulate sunrise and sunset. On the following day (Day 1), we created the treatments by separating first instar larvae were into cohorts of 50, which were then transferred to clean tubs containing $300 \mathrm{ml}$ of fresh water. Each treatment comprised of three replicate tubs $(3 \times 50$ individuals treatment ${ }^{-1}$ ). Resource levels were attained by adding 55, 110, 165 and $220 \mathrm{mg}$ of powdered fish food to the tubs, respectively. To allow resource depletion, tubs received two pulses of equal quantity. Half of the assigned quantity was provided on Day 1; the remaining half was provided on Day 4. After Day 4, resource levels were not adjusted but water volumes were topped up, if necessary.

\section{Fitness calculation}

We calculated $r_{\mathrm{m}}$ using a stage-structured matrix projection model (MPM), which describes change in a population over time (Equation 1; Caswell 1989):

$$
\mathbf{N}_{t+1}=\mathbf{M} \mathbf{N}_{t}
$$

where $\mathbf{N}_{t}$ is a vector of abundances in the stage classes at time $t$ and $\mathbf{M}$ is the projection matrix. The first row of $\mathbf{M}$ is populated with daily fecundity rate (the number of female offspring produced per female at age $i$ ). The sub-diagonal of $\mathbf{M}$ (Equation 1) is populated with the survival proportions from age $I$ to age $i+1$. Multiplying $\mathbf{N}_{t}$ and $\mathbf{M}$ sequentially across time intervals gives the stage-structured population dynamics. When the stable stage distribution of $\mathbf{N}_{t}$ is reached, the dominant eigenvalue of the system is the finite population rate of increase $(\lambda)$ (Caswell 1989). The intrinsic rate of population growth is then $r_{\mathrm{m}}=\log (\lambda)$; a population's inherent capacity to reproduce, and therefore a measure of population-level fitness (Birch 1948; Cole 1954; Savage et al. 2004). Positive and negative $r_{\mathrm{m}}$ values indicate growth and decline, respectively. We used the popbio R package to build and analyse the MPMs (Stubben \& Milligan 2007; R Core Team 2018). 


\section{Model parameterisation}

\section{Immature development time and immature and adult survival proportions}

The survival proportions for the matrix survival elements (the sub-diagonal of $\mathbf{M}$; Equation 1) were estimated using the survival R package (Therneau 2021). We defined the juvenile stage duration (i.e., hatching-to-adult) as the mean duration of transitioning into and out of that stage, and a fixed age of adult emergence at the mean age of emergence.

Juvenile development times for each treatment's MPM were predicted using a regression model (detailed in the 'Statistical analyses' section) that was parametrised with individual-level hatching-toadult times (days). Upon pupation, mosquitoes transferred to individual falcon tubes containing $5 \mathrm{ml}$ of tap water, which allowed pupa-to-adult development times and the lifespans of individual starved adults to be recorded. In the absence of food, adult lifespan is positively associated with emergent size, so it is a useful indicator of the carry over effects of temperature and competition in the larval habitat (Briegel 1990; Agnew et al. 2002).

\section{Daily fecundity rate}

Fecundity and body size are positively related in many insect taxa, including mosquitoes (Honěk 1993). For this reason, scaling relationships between fecundity and size are commonly used in predictions of population growth in Aedes (Livdahl \& Sugihara 1984; Juliano \& Lounibos 2005). We provide a detailed description of our method for estimating fecundity in Supplementary file 1. Briefly, we measured individual dry mass, and estimated lifetime fecundity using previously published datasets on the temperature-dependent scaling between mass and wing length (van den Heuvel 1963), and wing length and fecundity (Briegel 1990; Farjana \& Tuno 2012). Temperature-specific individual daily fecundity rate is required for the MPMs (Equation 1), so we divided lifetime fecundity by lifespan and multiplied by 0.5 (assuming a 1:1 offspring sex ratio). Later, we show that this much variation in the scaling of fecundity does not qualitatively change our results.

\section{Parameter sensitivity}

We used the standard errors of the survival and fecundity element estimates to account for how uncertainty in these traits is propagated through to the $r_{\mathrm{m}}$ estimate (Caswell 1989; Skalski et al. 2007). For survival, we used the standard errors estimated by the Kaplan-Meier survival function in the survival R package. For fecundity, we calculated the standard errors of the mean daily fecundity rates (Supplementary file 1-table S2) for each treatment using the Rmisc R package (Hope 2013). As an additional sensitivity analysis, we recalculated fitness using the upper and lower $95 \%$ CIs of the exponents for the scaling of size and lifetime fecundity (figure 3 ).

\section{Elasticity analysis}

We used elasticities to quantify the relative contributions of individual life history traits to $r_{\mathrm{m}}$. Elasticity, $e_{i j}$, measures the proportional effect on $\lambda$ of an infinitesimal change in an element of $\mathbf{M}$ (Equation 1) with all other elements held constant (the partial derivative) (Caswell et al. 1984; de Kroon et al. 1986). This partial derivative of $\lambda$, with respect to each element of $\mathbf{M}$, is $s_{i j}=\partial \lambda / \partial a_{i j}=v_{i} w_{j}$ with the dot product $\langle\mathbf{w}, \mathbf{v}\rangle=1$. Here, $\mathbf{w}$ is the dominant right eigenvector (the stage distribution vector of $\mathbf{M}$ ), $\mathbf{v}$ is the dominant left eigenvector (the reproductive value vector of $\mathbf{M}$ ), and $a_{i j}$ is the $i \times j^{\text {th }}$ element of $\mathbf{M}$. Elasticities can then be calculated using the relationship: $e_{i j}=a_{i j} / \lambda \times s_{i j}$. Multiplying an elasticity by $\lambda$ gives the absolute contribution of its corresponding $a_{i j}$ to $\lambda$ (Caswell et al. 1984; de Kroon et al. 1986). Absolute contributions for juvenile and adult elements were summed and changed proportionally to quantify the sensitivity of $r_{\mathrm{m}}$ to these traits. 


\section{Statistical analyses}

In the first instance, we used mixed effects models in the lme4 R package (Bates et al. 2015) to test for significant effects of our predictor variables on fitness traits. In the maximal models, temperature $\times$ resource level and replicate were fixed effect predictors and block was a random effect. However, the lower AIC scores from versions of the maximal model suggested that variation among replicates within blocks had a non-significant effect on trait responses. Therefore, for normally distributed trait data (adult lifespan and size), we used a full factorial linear regression model (LM) with temperature $\times$ resource level and replicate as fixed effects. Model diagnostics provided no evidence to suggest the development time data were normally distributed, so we used a generalised linear model (GLM) with family $=$ gamma and link = identity.

We tested the effect of resource level on the temperature dependence of daily per capita juvenile mortality rate by fitting an exponential function to the survival data with R package flexsurv (Jackson 2016). The final mortality model was obtained by dropping terms from the full model (consisting of temperature $\times$ resource level + replicate + block as fixed effect predictors). Terms were retained unless their removal worsened model fit $(\triangle \mathrm{AIC}>-2)$ (Supplementary file 1 -table 1). Maximum likelihood methods executed in flexsurv were used to estimate treatment-level juvenile mortality rates and their $95 \%$ CIs. Significant effects were interpreted when cIs were nonoverlapping.

\section{Quantifying the $r_{\mathrm{m}}$ thermal performance curve}

To determine how resource depletion affected the shape of the $r_{\mathrm{m}}$ TPC, we fitted several mathematical models that allow for negative values at both cold and hot extremes, including polynomial models using linear regression, as well as non-linear models with non-linear least squares (NLLS) using the rTPC R package (Padfield et al. 2021). Overall, the Lactin2 (Lactin et al. 1995) and Kamykowski (Kamykowski \& McCollum 1986) models were equally best-fitting according to the AIC (Supplementary file 1table 2). From these, we picked the Kamykowski model because it was better at describing the estimated $r_{\mathrm{m}}$ at our lowest resource level. This model is defined as

$$
r_{\mathrm{m}}(T)=a\left(1-\mathrm{e}^{-b\left(T-T_{\min }\right)}\right)\left(1-\mathrm{e}^{-c\left(T_{\max }-T\right)}\right),
$$

where $T\left({ }^{\circ} \mathrm{C}\right)$, and $T_{\max }$ and $T_{\min }$ are the high and low temperatures at which $r_{\mathrm{m}}$ becomes negative, respectively, and $a, b$, and $c$, are shape parameters without any biological meaning. Bootstrapping was used to calculate $95 \%$ prediction bounds for each $r_{\mathrm{m}}$ TPC (Padfield et al. 2021) and confidence intervals (CIs) around its $T_{\mathrm{opt}}$, as well as the thermal niche width $\left(T_{\max }-T_{\min }\right)$.

\section{Data accessibility}

All data for analyses will be available at publication from the Imperial College London Research Data Repository: https://doi.org/10.14469/hpc/8267

Prior to publication, data are available from the corresponding author on reasonable request.

A previous preprint version of this manuscript is available at:

https://doi.org/10.1101/2021.02.12.430918 


\section{Acknowledgements}

All authors contributed to the conception of the study and designed the experiments, L.J.C. provided the mosquitoes; P.J.H. and S.P. performed the modelling; P.J.H. collected the data and analysed it. P.J.H. wrote the first draft of the manuscript, and all authors contributed substantially to revisions.

\section{Competing interests}

We declare we have no competing interests.

\section{Funding}

This study was supported by Natural Environment Research Council (NE/L002515/1). We also acknowledge joint Centre funding from the UK Medical Research Council and Department for International Development (MR/R0156600/1).

\section{References}

Agnew, P., Hide, M., Sidobre, C. \& Michalakis, Y. (2002). A minimalist approach to the effects of density-dependent competition on insect life-history traits. Ecological Entomology, 27, 396-402.

Amarasekare, P. (2019). Effects of Climate Warming on Consumer-Resource Interactions: A Latitudinal Perspective. Frontiers in Ecology and Evolution, 7.

Amarasekare, P. \& Savage, V. (2012). A Framework for Elucidating the Temperature Dependence of Fitness. The American Naturalist, 179, 178-191.

Amarasekare, P. \& Simon, M.W. (2020). Latitudinal directionality in ectotherm invasion success. Proceedings of the Royal Society B: Biological Sciences, 287, 20191411.

Arguez, A., Durre, I., Applequist, S., Vose, R.S., Squires, M.F., Yin, X., et al. (2012). NOAA's 19812010 U.S. Climate Normals: An Overview. Bulletin of the American Meteorological Society, 93, $1687-1697$.

Arrivillaga, J. \& Barrera, R. (2004). Food as a limiting factor for Aedes aegypti in water-storage containers. Journal of vector ecology, 29, 11-20.

Bargielowski, I.E., Lounibos, L.P. \& Carrasquilla, M.C. (2013). Evolution of resistance to satyrization through reproductive character displacement in populations of invasive dengue vectors. Proceedings of the National Academy of Sciences of the United States of America, 110, 28882892.

Barreaux, A.M.G., Stone, C.M., Barreaux, P. \& Koella, J.C. (2018). The relationship between size and longevity of the malaria vector Anopheles gambiae (s.s.) depends on the larval environment. Parasites \& Vectors, 11, 485.

Barrera, R., Amador, M. \& Clark, G.G. (2006). Ecological Factors Influencing Aedes aegypti (Diptera: Culicidae) Productivity in Artificial Containers in Salinas, Puerto Rico. Journal of Medical Entomology, 43, 484-492.

Bates, D., Mächler, M., Bolker, B. \& Walker, S. (2015). Fitting linear mixed-effects models using lme4. Journal of Statistical Software, 67.

Beltran, R.S., Kilpatrick, A.M., Breed, G.A., Adachi, T., Takahashi, A., Naito, Y., et al. (2021). Seasonal resource pulses and the foraging depth of a Southern Ocean top predator. Proceedings of the Royal Society B: Biological Sciences, 288, rspb.2020.2817. 
Bestion, E., García-Carreras, B., Schaum, C.-E., Pawar, S. \& Yvon-Durocher, G. (2018). Metabolic traits predict the effects of warming on phytoplankton competition. Ecology Letters, 21, 655664.

Birch, L.C. (1948). The Intrinsic Rate of Natural Increase of an Insect Population. The Journal of Animal Ecology, 17, 15.

Briegel, H. (1990). Metabolic relationship between female body size, reserves, and fecundity of Aedes aegypti. Journal of Insect Physiology, 36, 165-172.

Caswell, H. (1978). A general formula for the sensitivity of population growth rate to changes in life history parameters. Theoretical Population Biology, 14, 215-230.

Caswell, H. (1989). Matrix population models construction, analysis, and interpretation. Natural Resource Modeling. Sinauer Associates, Sunderland, Massachusettes.

Caswell, H., Naiman, R.J. \& Morin, R. (1984). Evaluating the consequences of reproduction in complex salmonid life cycles. Aquaculture, 43, 123-134.

Cator, L.J., Johnson, L.R., Mordecai, E.A., El Moustaid, F., Smallwood, T.R.C., LaDeau, S.L., et al. (2020). The Role of Vector Trait Variation in Vector-Borne Disease Dynamics. Frontiers in Ecology and Evolution, 8, 1-25.

Chouaia, B., Rossi, P., Epis, S., Mosca, M., Ricci, I., Damiani, C., et al. (2012). Delayed larval development in Anopheles mosquitoes deprived of Asaia bacterial symbionts. BMC Microbiology, 12, S2.

Cole, L.C. (1954). The population consequences of life history phenomena. The Quarterly review of biology, 29, 103-137.

Couret, J., Dotson, E. \& Benedict, M.Q. (2014). Temperature, larval diet, and density effects on development rate and survival of Aedes aegypti (Diptera: Culicidae). PLoS ONE, 9, 1-9.

Craine, J.M., Fierer, N. \& McLauchlan, K.K. (2010). Widespread coupling between the rate and temperature sensitivity of organic matter decay. Nature Geoscience, 3, 854-857.

Cross, W.F., Hood, J.M., Benstead, J.P., Huryn, A.D. \& Nelson, D. (2015). Interactions between temperature and nutrients across levels of ecological organization. Global Change Biology, 21, $1025-1040$.

Diagne, C., Leroy, B., Vaissière, A.-C., Gozlan, R.E., Roiz, D., Jarić, I., et al. (2021). High and rising economic costs of biological invasions worldwide. Nature, In Press.

Dickson, L.B., Jiolle, D., Minard, G., Moltini-Conclois, I., Volant, S., Ghozlane, A., et al. (2017). Carryover effects of larval exposure to different environmental bacteria drive adult trait variation in a mosquito vector. Science Advances, 3, e1700585.

Dye, C. (1984). Models for the Population Dynamics of the Yellow Fever Mosquito, Aedes aegypti. The Journal of Animal Ecology, 53, 247.

Farjana, T. \& Tuno, N. (2012). Effect of body size on multiple blood feeding and egg retention of Aedes aegypti (L.) and Aedes albopictus (Skuse) (Diptera: Culicidae). Medical Entomology and Zoology, 63, 123-131.

Farjana, T., Tuno, N. \& Higa, Y. (2012). Effects of temperature and diet on development and interspecies competition in Aedes aegypti and Aedes albopictus. Medical and Veterinary Entomology, 26, 210-217.

García-Carreras, B., Sal, S., Padfield, D., Kontopoulos, D.-G., Bestion, E., Schaum, C.-E., et al. (2018). Role of carbon allocation efficiency in the temperature dependence of autotroph growth rates. Proceedings of the National Academy of Sciences, 115, E7361-E7368. 
Hery, L., Guidez, A., Durand, A.-A., Delannay, C., Normandeau-Guimond, J., Reynaud, Y., et al. (2021). Natural Variation in Physicochemical Profiles and Bacterial Communities Associated with Aedes aegypti Breeding Sites and Larvae on Guadeloupe and French Guiana. Microbial Ecology, 81, 93-109.

van den Heuvel, M.J. (1963). The Effect of Rearing Temperature on the Wing Length, Thorax Length, Leg Length and Ovariole Number of the Adult Mosquito, Aedes Aegypti (L.). Transactions of the Royal Entomological Society of London, 115, 197-216.

Honěk, A. (1993). Intraspecific Variation in Body Size and Fecundity in Insects: A General Relationship. Oikos, 66, 483.

Hope, R.M. (2013). Rmisc: Rmisc: Ryan Miscellaneous.

Huey, R.B. \& Berrigan, D. (2001). Temperature, Demography, and Ectotherm Fitness. The American Naturalist, 158, 204-210.

Huey, R.B. \& Kingsolver, J.G. (2019). Climate warming, resource availability, and the metabolic meltdown of ectotherms. American Naturalist, 194.

Huxley, P.J., Murray, K.A., Pawar, S. \& Cator, L.J. (2021). The effect of resource limitation on the temperature dependence of mosquito population fitness. Proceedings of the Royal Society B: Biological Sciences, 288, rspb.2020.3217.

Iwamura, T., Guzman-Holst, A. \& Murray, K.A. (2020). Accelerating invasion potential of disease vector Aedes aegypti under climate change. Nature Communications, 11, 2130.

Jackson, C. (2016). flexsurv: A Platform for Parametric Survival Modeling in R. Journal of Statistical Software, 70, 1-33.

Juliano, S.A. (1998). Species Introduction and Replacement among Mosquitoes: Interspecific Resource Competition or Apparent Competition? Ecology, 79, 255.

Juliano, S.A. \& Lounibos, L.P. (2005). Ecology of invasive mosquitoes: effects on resident species and on human health. Ecology Letters, 8, 558-574.

Kammenga, J.E., Busschers, M., Straalen, N.M. Van, Jepson, P.C. \& Bakker, J. (1996). Stress Induced Fitness Reduction is Not Determined by the Most Sensitive Life-Cycle Trait. Functional Ecology, 10, 106.

Kamykowski, D. \& McCollum, S.A. (1986). The temperature acclimatized swimming speed of selected marine dinoflagellates. Journal of Plankton Research, 8, 275-287.

Kooijman, S.A.L.M. (2000). Dynamic energy and mass budgets in biological systems. Cambridge University Press, Cambridge.

de Kroon, H., Plaisier, A., van Groenendael, J. \& Caswell, H. (1986). Elasticity: The Relative Contribution of Demographic Parameters to Population Growth Rate. Ecology, 67, 1427-1431.

Lactin, D.J., Holliday, N.J., Johnson, D.L. \& Craigen, R. (1995). Improved Rate Model of Temperature-Dependent Development by Arthropods. Environmental Entomology, 24, 68-75.

Lehmann, P., Ammunét, T., Barton, M., Battisti, A., Eigenbrode, S.D., Jepsen, J.U., et al. (2020). Complex responses of global insect pests to climate warming. Frontiers in Ecology and the Environment, 18, 141-150.

Liikanen, A., Murtoniemi, T., Tanskanen, H., Väisänen, T. \& Martikainen, P.J. (2002). Effects of temperature and oxygen availability on greenhouse gas and nutrient dynamics in sediment of a eutrophic mid-boreal lake. Biogeochemistry, 59, 269-286. 
Lister, B.C. \& Garcia, A. (2018). Climate-driven declines in arthropod abundance restructure a rainforest food web. Proceedings of the National Academy of Sciences, 115, E10397-E10406.

Livdahl, T.P. \& Sugihara, G. (1984). Non-Linear Interactions of Populations and the Importance of Estimating Per Capita Rates of Change. The Journal of Animal Ecology, 53, 573.

Merritt, R.W., Dadd, R.H. \& Walker, E.D. (1992). Feeding behaviour, natural food, and nutritional relationships and larval mosquitoes. Annual Review of Entomology, 349-76.

Mordecai, E.A., Caldwell, J.M., Grossman, M.K., Lippi, C.A., Johnson, L.R., Neira, M., et al. (2019). Thermal biology of mosquito-borne disease. Ecology Letters, 22, 1690-1708.

Mordecai, E.A., Ryan, S.J., Caldwell, J.M., Shah, M.M. \& LaBeaud, A.D. (2020). Climate change could shift disease burden from malaria to arboviruses in Africa. The Lancet Planetary Health, 4, e416-423.

Ostfeld, R.S. \& Keesing, F. (2000). Pulsed resources and community dynamics of consumers in terrestrial ecosystems. Trends in Ecology \& Evolution, 15, 232-237.

Padfield, D., O'Sullivan, H. \& Pawar, S. (2021). rTPC and nls.multstart: A new pipeline to fit thermal performance curves in R. Methods in Ecology and Evolution, 12, 1138-1143.

Parmesan, C. (2006). Ecological and evolutionary responses to recent climate change. Annual Review of Ecology, Evolution, and Systematics, 37, 637-669.

R Core Team. (2018). R: A language and environment for statistical computing.

Ryan, S.J., Carlson, C.J., Tesla, B., Bonds, M.H., Ngonghala, C.N., Mordecai, E.A., et al. (2021). Warming temperatures could expose more than 1.3 billion new people to Zika virus risk by 2050. Global Change Biology, 27, 84-93.

Savage, V.M., Gillooly, J.F., Brown, J.H., West, G.B. \& Charnov, E.L. (2004). Effects of Body Size and Temperature on Population Growth. The American Naturalist, 163, 429-441.

Shocket, M.S., Verwillow, A.B., Numazu, M.G., Slamani, H., Cohen, J.M., El Moustaid, F., et al. (2020). Transmission of West Nile and five other temperate mosquito-borne viruses peaks at temperatures between $23^{\circ} \mathrm{C}$ and $26^{\circ} \mathrm{C}$. eLife, $9,1-67$.

Siegel, P., Baker, K.G., Low-Décarie, E. \& Geider, R.J. (2020). High predictability of direct competition between marine diatoms under different temperatures and nutrient states. Ecology and Evolution, 10, 7276-7290.

Skalski, J.R., Millspaugh, J.J., Dillingham, P. \& Buchanan, R.A. (2007). Calculating the variance of the finite rate of population change from a matrix model in Mathematica. Environmental Modelling \& Software, 22, 359-364.

Smith, T.P., Thomas, T.J.H., García-Carreras, B., Sal, S., Yvon-Durocher, G., Bell, T., et al. (2019). Community-level respiration of prokaryotic microbes may rise with global warming. Nature Communications, 10, 5124.

Southwood, T.R., Murdie, G., Yasuno, M., Tonn, R.J. \& Reader, P.M. (1972). Studies on the life budget of Aedes aegypti in Wat Samphaya, Bangkok, Thailand. Bulletin of the World Health Organization, 46, 211-226.

Souza, R.S., Virginio, F., Riback, T.I.S., Suesdek, L., Barufi, J.B. \& Genta, F.A. (2019). Microorganism-Based Larval Diets Affect Mosquito Development, Size and Nutritional Reserves in the Yellow Fever Mosquito Aedes aegypti (Diptera: Culicidae). Frontiers in Physiology, 10, 1-24.

Steinwascher, K. (1982). Relationship Between Pupal Mass and Adult Survivorship and Fecundity for Aedes aegypti. Environmental Entomology, 11, 150-153. 
Stubben, C. \& Milligan, B. (2007). Estimating and Analyzing Demographic Models Using the popbio Package in R. Journal of Statistical Software, 22, 1-23.

Subra, R. \& Mouchet, J. (1984). The regulation of preimaginal populations of Aedes aegypti (L.) (Diptera: Culicidae) on the Kenya coast. Annals of Tropical Medicine \& Parasitology, 78, 6370.

Taheri, S., Naimi, B., Rahbek, C. \& Araújo, M.B. (2021). Improvements in reports of species redistribution under climate change are required. Science Advances, 7, eabe1110.

Therneau, T. (2021). A Package for Survival Analysis in R.

Thomas, M.K., Aranguren-Gassis, M., Kremer, C.T., Gould, M.R., Anderson, K., Klausmeier, C.A., et al. (2017). Temperature-nutrient interactions exacerbate sensitivity to warming in phytoplankton. Global Change Biology, 23, 3269-3280.

Trisos, C.H., Merow, C. \& Pigot, A.L. (2020). The projected timing of abrupt ecological disruption from climate change. Nature, 580, 496-501.

WHO. (2020). Multisectoral Approach to the Prevention and Control of Vector-Borne Diseases. Geneva.

Yang, L.H., Bastow, J.L., Spence, K.O. \& Wright, A.N. (2008). What Can We Learn From Resource Pulses? Ecology, 89, 621-634.

Yee, D.A. \& Juliano, S.A. (2012). Concurrent effects of resource pulse amount, type, and frequency on community and population properties of consumers in detritus-based systems. Oecologia, $169,511-522$.

Yee, D.A., Kaufman, M.G. \& Juliano, S.A. (2007). The significance of ratios of detritus types and micro-organism productivity to competitive interactions between aquatic insect detritivores. Journal of Animal Ecology, 76, 1105-1115. 


\section{Supplementary Files}

This is a list of supplementary files associated with this preprint. Click to download.

- CommsBSI.pdf 